УДК 372.87

\title{
ТЕОРЕТИКО-МЕТОДОЛОГИЧЕСКИЕ АСПЕКТЫ ПЕДАГОГИЧЕСКОГО ПОТЕНЦИАЛА КОМПЬЮТЕРНЫХ ТЕХНОЛОГИЙ В ОБУЧЕНИИ МЛАДШИХ ШКОЛЬНИКОВ РИСУНКУ В СИСТЕМЕ ДОПОЛНИТЕЛЬНОГО ОБРАЗОВАНИЯ
}

\author{
Беков Магомед Алаудинович \\ студент \\ ФГБОУ ВО «Московский педагогический \\ государственный университет им. В.И. Ленина»
}

\begin{abstract}
Аннотация: Статья посвящена теоретико-методологическим аспектам, характеризующим педагогический потенциал современных компьютерных технологий в обучении младших школьников рисунку в учреждениях дополнительного образования. Цель - обобщение теоретико-методологических аспектов для выбора лучших направлений активации педагогического потенциала компьютерных технологий в предметной сфере. Ключевые методы - анализ педагогической литературы, сравнение с практикой работы профессиональных художников-иллюстраторов, педагогическое моделирование. Результаты: представлен комплекс применения компьютерных технологий в обучении младших школьников рисунку в системе дополнительного образования. Описаны возможности, потенциал и ограничения применения компьютерных технологий как инструментов для рисования, помощников детей в творчестве, а также заместителей учителей. Предложена авторская педагогическая модель активации потенциала компьютерных технологий в обучении младших школьников рисунку в системе дополнительного образования. Выводы: грамотная реализация лучших возможностей применения компьютерных технологий в педагогической практике обучения младших школьников рисунку на основе передовых научнометодологических материалов, а также новых разработок, обеспечивающих селективное совершенствование имеющихся методов и подходов, окажет всестороннее содействие приобщению всех заинтересованных детей к многообразным видам изобразительного творчества, способствуя, тем самым,
\end{abstract}


потенциальному обеспечению прорывных результатов в дополнительном образовании.

Ключевые слова: Педагогический потенциал компьютерных технологий, обучение рисунку, младшие школьники, информационнокоммуникационные технологии, художественное образование, система дополнительного образования, дополнительное художественное образование.

\title{
THEORETICAL AND METHODOLOGICAL ASPECTS OF THE PEDAGOGICAL POTENTIAL OF COMPUTER TECHNOLOGIES IN TEACHING DRAWING TO YOUNGER SCHOOLCHILDREN IN THE SYSTEM OF ADDITIONAL EDUCATION
}

\section{Bekov Magomed Alaudinovich}

\begin{abstract}
The article is devoted to theoretical and methodological aspects that characterize the pedagogical potential of modern computer technologies in teaching drawing to younger students in institutions of additional education. The aim is to generalize theoretical and methodological aspects for choosing the best directions for activating the pedagogical potential of computer technologies in the subject area. Key methods - analysis of pedagogical literature, comparison with the practice of professional illustrators, pedagogical modelling. Results: a set of application of computer technologies in teaching drawing to younger students in the system of additional education is presented. The possibilities, potential and limitations of the use of computer technologies as tools for drawing, assistants to children in creativity, as well as substitute teachers are described. The author's pedagogical model for activating the potential of computer technologies in teaching drawing to younger schoolchildren in the system of additional education is proposed. Conclusions: the competent implementation of the best opportunities for the use of computer technology in the pedagogical practice of teaching primary school students to draw on the basis of advanced scientific and methodological materials, as well as new developments that provide selective improvement of existing methods and approaches, will provide comprehensive assistance in introducing all interested children to various types of fine arts, thereby contributing to the potential for breakthrough outcomes in continuing education.
\end{abstract}




\section{ОБРАЗОВАТЕЛЬНЫЕ ТЕХНОЛОГИИ \\ В СОВРЕМЕННОМ УЧЕБНО-ВОСПИТАТЕЛЬНОМ ПРОСТРАНСТВЕ}

Key words: Pedagogical potential of computer technologies, teaching drawing, junior schoolchildren, information and communication technologies, art education, additional education system, additional art education.

Введение. Современное художественное образование неизбежно сталкивается с аспектами, связанными с необходимостью интеграции компьютерных технологий (входящих в комплекс информационнокоммуникационных технологий, или ИКТ) в образовательный процесс [1]. ИКТ получают хорошие рекомендации как средства и инструменты педагогической деятельности, в частности, в рамках проблемной, развивающей педагогике и по многим другим направлениям [2]. Однако аспекты применения компьютерных технологий в системе художественного образования остаются дискуссионными. Это связано и с нехваткой педагогического опыта в предметной сфере, и с опасениями по поводу того, что ИТК ограничат реализацию творчества детей и лимитируют достижение других образовательных задач, и с недостаточным внедрением наиболее перспективных компьютерных технологий в образовательный процесс соответствующая проблематика, зачастую, существует в тесной взаимосвязи.

Речь идет, безусловно, не о выборочном применении технологий, например для хранения сведений об успеваемости учащихся в «электронном дневнике» или о проведении занятий в системе дополнительного образования (далее также ДО) в дистанционном формате, хотя данные действия осуществляются благодаря развитию компьютерных технологий. В настоящей публикации рассматриваются педагогические аспекты применения компьютерных технологий для достижения задач обучения. Объект исследования - обучение школьников рисунку в системе дополнительного образования. Целью исследования выступает обобщение теоретикометодологических аспектов для выбора лучших направлений активации педагогического потенциала компьютерных технологий в обучении младших школьников рисунку в системе дополнительного образования.

Материалы и методы. Публикация представляет собой результат критического осмысления методологии и теории применения компьютерных технологий в обучении детей рисунку в системе дополнительного образования. Для достижения цели исследования, применены методы анализа и синтеза положений, представленных в научной литературе, индукции и дедукции, 


\section{ОБРАЗОВАТЕЛЬНЫЕ ТЕХНОЛОГИИ \\ В СОВРЕМЕННОМ УЧЕБНО-ВОСПИТАТЕЛЬНОМ ПРОСТРАНСТВЕ}

диалектический и системный подход к комплексному изучению современных педагогических технологий и практических аспектов их применения. Возможности применения компьютерных технологий в обучении младших школьников рисунку в системе дополнительного образования исследуются в сопоставлении с аспектами практической творческой деятельности современных художников, в частности художников-иллюстраторов, которые в силу комплекса причин активно пользуются ИКТ в своей практической деятельности, или полностью перешли на ИКТ. Для систематизации теоретикометодологических аспектов педагогического потенциала компьютерных технологий в предметной сфере в целях выработки универсального подхода к применению их на практике, использован метод педагогического моделирования.

\section{Основная часть.}

В целом, следует отметить, что, как и в любой другой сфере педагогики что применение компьютерных технологий в художественном образовании школьников, несмотря на очевидный педагогический потенциал, вызывает многочисленные споры [3].

Основной тезис, характерный для многих научных школ, заключается в том, что ИКТ не должны подменять ребёнка как творческую единицу, угнетать его творчество, стимулировать способы не креативного решения поставленных задач [4]. С представленным тезисом сложно не согласиться, однако с оговоркой о том, что ИКТ должны в принципе располагать соответствующими свойствами: в случае с применением известного и массово доступного в современных российских условиях программного обеспечения, нельзя однозначно утверждать о тотальной способности компьютеров рисовать за детей. Проблематика по-прежнему заключается в доступности технологий, в знаниях педагогов о них и в навыках практического применения.

Анализ педагогической литературы [5-7] показывает, кто компьютерные технологии в обучении детей рисунку (безотносительно возраста ребенка и вида образования) могут быть применены в трех основных ипостасях:

1) как инструмент и средство рисования;

2) как помощника художника;

3) как учителя рисунку.

Аспекты и направления возможного применения компьютерных технологий в обучении младших школьников рисунку в системе 
дополнительного образования образуют своеобразную педагогическую систему — триаду «ТНТ» (англ. “tool-help-tutor”, «инструмент - помощь - наставник»), см. Рисунок 1. Хотя на практике все три аспекта применения ИКТ зачастую могут комбинироваться, между тем каждый из них имеет характерные особенности, которые представляется целесообразным рассмотреть по отдельности.

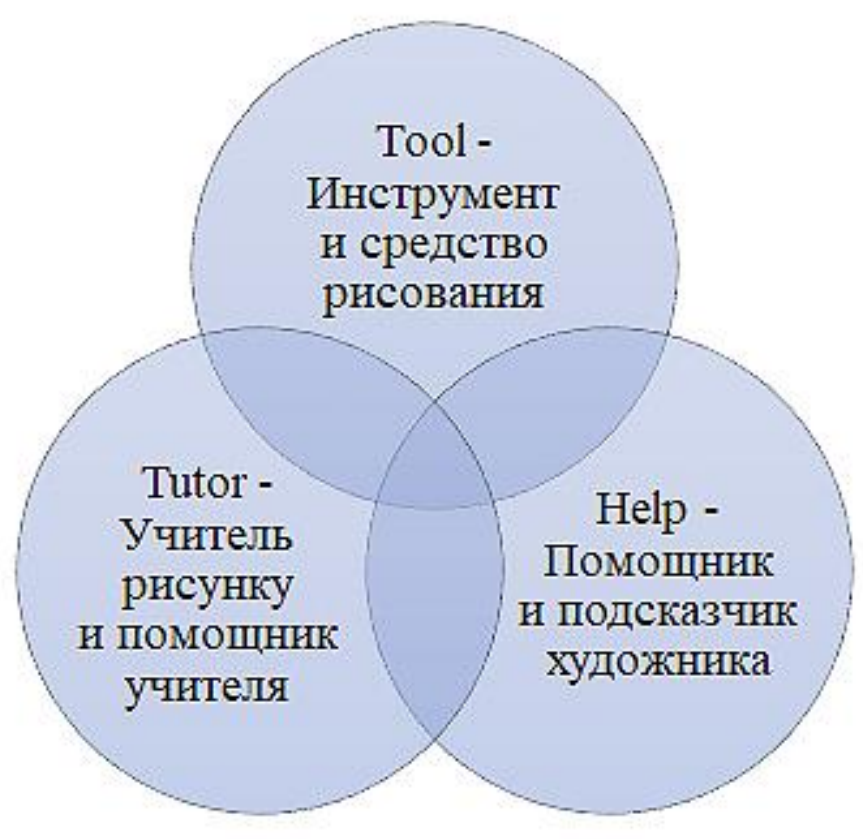

\section{Рис. 1. ТНТ-комплекс применения компьютерных технологий в обучении младших школьников рисунку в системе ДО}

Источник: Разработано автором

Компьютерные технологии как инструменты рисования. По поводу допустимости и применимости компьютерных технологий как инструментов и средств для рисования в профессиональном сообществе практически не возникает дискуссий - многие его представители давно и успешно приняли арсенал соответствующих технологий на свое «вооружение». В частности, современные художники-иллюстраторы, как, например, известная британская детская художница советского происхождения Элина Эллис [8] отмечают, что в своей практической деятельности компьютерные технологии полностью заменили традиционные карандаши, кисти-краски, бумагу и холст; между тем, речь идет именно о таких технологиях, которые просто заменяют инструменты 


\section{ОБРАЗОВАТЕЛЬНЫЕ ТЕХНОЛОГИИ \\ В СОВРЕМЕННОМ УЧЕБНО-ВОСПИТАТЕЛЬНОМ ПРОСТРАНСТВЕ}

творчества на электронные - монитор планшета или другого приспособления становится мольбертом и холстом (альбомным листом и др.), стилус карандашом или кистью. Краски, чернила, грифель заменяются уже инструментами компьютерной программы. Среди преимуществ технологии прежде всего, мобильность; художник может начать и продолжить творчество в любом месте, необходимо лишь иметь при себе нетяжелую технику и гарантировать наличие достаточного заряда. Компьютерные технологии позволяют намного легче исправлять ошибки - в ряде случаев, это укрепляет свободу творчества, по меньшей мере потому, что художнику не приходится держать в голове возможные последствия ошибок. Соответствующие аспекты находят полноценное применение в педагогике: занятие рисунку в учреждении ДО может быть успешно и с минимальными затруднениями продолжено дома. Домашнее задание может быть выполнено в необычных условиях - в поездке, на даче, на отдыхе или, например, в стационаре. Мобильность технологии существенно усиливает возможности инклюзивности в обучении рисунку, вовлекая в образовательный процесс, в частности, маломобильных детей. Кроме того, когда электронные инструменты и средства рисования всегда находятся «под рукой», это способствует созданию условий для реализации художественного таланта в части того, что ребенок может начать рисовать что угодно и где угодно в любой подходящий для этого момент. А, как известно, создание условий для творчества без границ - важнейшее направление развития современной системы художественного образования [9]. Впрочем, немаловажно обеспечивать применение качественных инструментов технологий, - то есть таких, которыми воспользовались бы и уважающие себя профессиональные художники; несовершенство технологий, а также их несовместимость (когда на занятии в учреждении ДО применяются одни ИКТ, а в домашней работе - другие), могут полностью нивелировать положительный педагогический эффект. Говоря о несовершенстве технологий в качестве наиболее иллюстративного примера использование технологий с плохой или замеленной передачей движения стилуса на электронный холст, что само по себе может вызвать проблемы в когнитивной сфере у ребенка, преодоление которых не выступает ни типичной, ни ожидаемой педагогической задачей. Безусловно, такие ситуации в практике дополнительного художественного образования представляются недопустимыми, но из-за недостаточности финансирования и профессиональных компетенций, как правило, именно 


\section{ОБРАЗОВАТЕЛЬНЫЕ ТЕХНОЛОГИИ \\ В СОВРЕМЕННОМ УЧЕБНО-ВОСПИТАТЕЛЬНОМ ПРОСТРАНСТВЕ}

подобная негативная ситуация как раз и складывается в отечественной педагогической практике.

Компьютерные технологии как помощники детей при рисовании. Аспекты помощи художнику с применением ИКТ достаточно многогранны. Современные иллюстраторы, к примеру, также не ограничивают себя, например, в использовании таких средств, как копирование и масштабирование элементов и объектов, в особенности ранее созданных самим художником - это позволяет повысить продуктивность труда, обеспечивает единство внешнего выражения в серийных произведениях, например таких, как комиксы [8]. Другой важный инструмент, - автокоррекция ошибок - его предлагают многочисленные программы для рисования, и им активно пользуются все те же иллюстраторы, существенно упрощая свою работу. Педагогическая ценность соответствующей помощи имеет, в целом, дискуссионный характер. Перед ребенком, особенно младшим школьником, не стоит задача оперативно тиражировать свое творчество и успевать «к дедлайну». Напротив, важно планомерно, в том числе, через собственные ошибки, учиться рисовать предметы, познавать окружающий мир и внутреннее «Я» через рисунок [10]. «Автоматизированная помощь» в этом случае будет играть роль не помощника, a, скорее, наоборот. Имеются сомнения и в том, позволит ли ИКТ формировать и развивать уникальный стиль ребенка. Например, если ребенок будет копировать свои лучшие решения, то сможет ли он воспроизвести их вне компьютерной программы? У упомянутых художников-иллюстраторов всегда имеется свой неповторимый, авторский стиль в рисунке, но сформировался бы этот стиль, если бы они с детства занимались форменным самоплагиатом?

Таким образом, избыточная помощь со стороны «умных технологий» может навредить, но едва ли данное обстоятельство выступает основанием для отказа от применения электронных помощников как таковых, тем более при работе с наиболее молодой аудиторией. В данном контексте хотелось бы напомнить не только об организационных вопросах (ИКТ смогут подменять педагогов в малозначимых технических аспектах, расширяя традиционно ограниченный организационный ресурс учреждений ДО), но и о том, что дети младшего школьного возраста в силу возрастных особенностей остро нуждаются в помощи и поддержке, в том числе как фактора мотивации. Ребенок может прекратить занятия рисованием, если будет постоянно терпеть неудачи в выполнении заданий, - получение периодической помощи «от 


\section{ОБРАЗОВАТЕЛЬНЫЕ ТЕХНОЛОГИИ \\ В СОВРЕМЕННОМ УЧЕБНО-ВОСПИТАТЕЛЬНОМ ПРОСТРАНСТВЕ}

компьютера» может снизить педагогические риски, тем более что педагог как оператор настроек компьютерной программы сам имеет возможность конструировать пространство художественного образования - например, устанавливая разрешения программной помощи или исключая их. Соответствующие рекомендации могут передаваться родителям.

Кроме того, в задачи массового художественного образования входит не только воспитание талантов, но и предоставление возможностей для свободы творчеству каждому желающему, расширение кругозора, приобщение к сокровищам культуры, формирование эстетики и другие. «Компьютерные помощники», если ими распоряжаться разумно и не злоупотреблять, органично дополнят существующие педагогические технологии и позволят всесторонне развивать практику младших школьников рисунку в системе дополнительного образования, повышая ее педагогическую эффективность.

Тем самым, учитель рисования в организациях ДО призван выступать разумным оператором настроек компьютерных программ. В данном контексте видится важным существенно повышать ИКТ-компетенции педагога дополнительного образования, что потребует, помимо прочего, единства применяемого программного обеспечения и образовательных методик.

Компьютерные технологии как помощники и заместители педагога. В силу недостаточной развитости таких технологий, как, в частности искусственный интеллект, постановка вопроса о возможности полной замены учителя на «умную машину», тем более в части работы с контингентом младших школьников, в настоящее время не является остро актуальной, хотя и должна учитываться в перспективных научных исследованиях. Речь идет об использовании отдельных обучающих программ, которые, прежде всего, применяются для укрепления и развития некоторых умений и навыков в дополнение к деятельности педагога или в связи с его вынужденной заменой. С учетом особенностей и возможностей применения ИКТ как «заместителей учителя», роль современного педагога системы дополнительного образования локализуется, в частности, в контексте выработки рекомендаций по выбору лучших программ для обучения, содействия формированию и развитию определенных художественных умений, прежде всего, первичных.

Подобные программы могут быть по-разному полезными для школьников с различным уровнем подготовки, загруженностью досуга и др. Их селективное применение должно быть ориентировано на достижение педагогического 


\section{ОБРАЗОВАТЕЛЬНЫЕ ТЕХНОЛОГИИ \\ В СОВРЕМЕННОМ УЧЕБНО-ВОСПИТАТЕЛЬНОМ ПРОСТРАНСТВЕ}

эффекта - вряд ли работа с программой способна причинить существенный вред, к примеру, развитию ребенка, но бесполезное расходование времени, а также негативное влияние на заинтересованность ребенка в рисовании могут рассматриваться в числе педагогических рисков. И, в целом, злоупотребление нерелевантным педагогическим инструментарием может иметь негативный эффект, вплоть до угнетения творческих способностей ребенка. В перспективе развития отечественной системы ДО - разработка и техническая реализация адаптированных, а также авторских обучающих программ, подготовленных отечественными педагогами и предназначенных для дифференцированного использования в педагогической практике.

Педагогическая модель активации потенциала компьютерных технологий в обучении младших школьников рисунку в системе дополнительного образования. Для воплощения системы передовых педагогических технологий и лучшего отраслевого опыта в педагогическую практику, представляется целесообразным применить метод педагогического моделирования, синтезировав теоретико-методологические характеристики потенциала новых технологий.

С учетом изложенного, на Рисунке 2 в графическом виде представлена разработанная автором педагогическая модель активации потенциала компьютерных технологий в обучении младших школьников рисунку в системе дополнительного образования.

Основу предлагаемой педагогической модели составляют цели и задачи обучения младших школьников рисунку в системе дополнительного образования и ИКТ как комплексный инструментарий фасилитации их достижения, а также селективный подход к применению в педагогической практике, в рамках которого компьютерные технологии призваны выступать своеобразными фасилитаторами креативного мышления и развития детского творчества.

Предложенная теоретико-методологическая педагогическая модель подлежит апробации на практике, по результатам которой может быть принято решение о массовом внедрении в педагогическую деятельность. 


\section{ОБРАЗОВАТЕЛЬНЫЕ ТЕХНОЛОГИИ \\ В СОВРЕМЕННОМ УЧЕБНО-ВОСПИТАТЕЛЬНОМ ПРОСТРАНСТВЕ}

Задачи дополнительного художественного образования, на которые воздействует применение компьютерньх технологий:

- фасилитация креативного мышшления; содействие детскому творчеству и самореализацин; расшшрение кругозора и развитие инднвндуальной эстетикн; повышение заинтересованности в изобразительном твортеспве повышение доступности дополнительного художеспенного образования мл. пшкольников

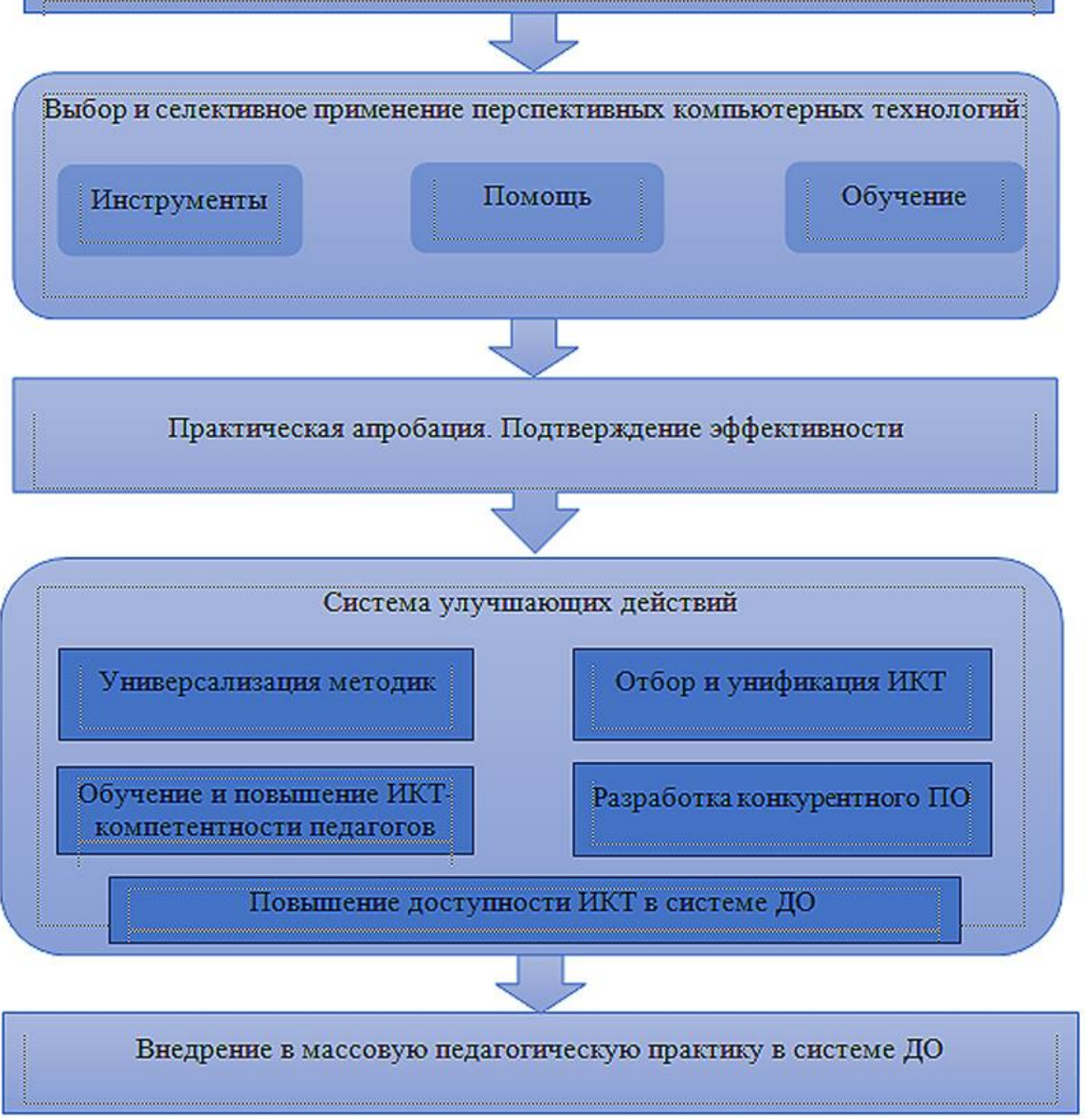

Рис. 2. Педагогическая модель активации потенциала компьютерных технологий в обучении младших школьников рисунку в системе дополнительного образования 


\section{ОБРАЗОВАТЕЛЬНЫЕ ТЕХНОЛОГИИ \\ В СОВРЕМЕННОМ УЧЕБНО-ВОСПИТАТЕЛЬНОМ ПРОСТРАНСТВЕ}

Источник: Разработано автором

Заключение. Таким образом, грамотная реализация лучших возможностей применения компьютерных технологий в педагогической практике обучения младших школьников рисунку на основе передовых научнометодологических материалов, а также новых разработок, обеспечивающих селективное совершенствование имеющихся методов и подходов, окажет всестороннее содействие приобщению всех заинтересованных детей к многообразным видам изобразительного творчества, способствуя, тем самым, потенциальному обеспечению прорывных результатов в дополнительном образовании. Для этих целей необходимо обеспечить дальнейшее повышение квалификации педагогов и обмен передовым опытом, универсализацию методик младших школьников рисунку с применением ИКТ, расширение доступности с одновременной унификацией компьютерных технологий, применяемых в системе дополнительного художественного образования.

\section{Список литературы}

1. Товпич И. О. Метатехнология формирования системы непрерывного (сквозного) образования: интеграция информационных и художественных средств обучения в системе общего и дополнительного образования детей //Интернет и цифровое пространство: постматериальные ценности молодежи. 2018. - С. 210-214.

2. Андреева Э. В. Применение ИКТ в преподавании педагогики: рефлексивно-развивающий аспект // StudNet. - 2020. - №11. - URL: https:// cyberleninka.ru/article/n/primenenie-ikt-v-prepodavanii-pedagogiki-refleksivnorazvivayuschiy-aspekt (дата обращения: 24.01.2022).

3. Красильников И. М. Педагогический потенциал цифровых технологий и его реализация в художественном образовании// Отечественная и зарубежная педагогика. - 2019. - №2 (59). - С. 95-104.

4. Kupers E. et al. Children's creativity: A theoretical framework and systematic review //Review of Educational Research. 2019. Vol. 89. N. 1. P. 93-124.

5. Лю С. Мультимедийные образовательные средства в обучении детей изобразительному искусству // «Инновационное развитие современной науки: проблемы, закономерности, перспективы»: сборник статей VII Международной 
научно-практической конференции: в 2 ч. - Пенза: Наука и Просвещение, 2018. - C. 231-233.

6. Дмитриевская Е.А., Аманжолов С. А. Использование информационнокомпьютерных технологий на уроках изобразительного искусства. За и против! // «Современные информационные технологии в образовании, науке и промышленности»: Сборник научных трудов XVII Международной конференции, XV Международного конкурса научных и научно-методических работ. Отв. редактор и составитель Т.В. Пирязева. - М.: Общество с ограниченной ответственностью «Издательство "Экон-Информ"», 2020. - С. 46-49.

7. Selezneva Y., Pakhomova V. Influence of interpersonal relationships on acquaintance with digital technologies //E3S Web of Conferences. - EDP Sciences, 2021. - Vol. 273. - P. 11010.

8. Как стать иллюстратором детских книг и найти свой визуальный язык. Рассказывает Элина Эллис. - URL: https://www.labirint.ru/now/elina-ellis (дата обращения: 24.01.2022).

9. Куприна, Н. Г. Реализация воспитательного потенциала искусства в условиях дополнительного художественного образования [Электронный pecypc]: монография / Н. Г. Куприна, Э. Д. Оганесян; Урал. гос. пед. ун-т. Электрон. дан. - Екатеринбург: [б. и.], 2019. - 1 электрон. опт. диск (CD-ROM).

10. Стрижко Э. А. Естественный рисунок- новое начало познания мира в котором живём и на кот.живём//Colloquium-journal. 2018. №. 13-1. С. 19-37. 